\title{
CORPORATE SOCIAL RESPONSIBILITY DI KABUPATEN KARAWANG
}

\author{
M. Gary Gagarin Akbar, S.H., M.H Email : gary.akbar@ubpkarawang.ac.id \\ Muhamad Abas, S.H., M.H Email : muhamad.abas@ubpkarawang.ac.id \\ Lia Amaliya, S.H., M.H Email : liaAmaliya@ubpkarawang.ac.id
}

Fakultas Hukum Universitas Buana Perjuangan Karawang

\begin{abstract}
Abstrak
Corporate social responsibility merupakan kewajiban dari peraturan perundang-undangan yang dibebankan kepada setiap perusahaan agar memperhatikan lingkungan sekitar dimana perusahaan tersebut berada. Tujuan corporate social responsibility adalah untuk ikut berkontribusi bagi kesejahteraan masyarakat dan melakuka pembangunan secara berkesinambungan bersama pemerintah daerah. Permasalahan yang diangkat dalam penelitian ini adalah bagaimana impelentasi kewajiban hukum perusahaan dalam memberikan corporate social responsibility di kabupaten karawang. Metode yang digunakan adalah penelitian yuridis empiris. Kesimpulan yang diperoleh adalah belum adanya kesadaran hukum bagi perusahaan di Kabupaten Karawang untuk memberikan corporate social responsibility kepada lingkungan dan Kabupaten Karawang pada umumnya. Padahal menurut ketentuan perundang-undangan perusahaan wajib memberikan corporate social responsibility sebagai kewajibannya untuk melakukan pembangunan ekonomi dan masyarakat yang ada di suatu daerah.
\end{abstract}

\section{Kata Kunci : Corporate Social Responsibility, Perusahaan dan Kewajiban Hukum}

\section{Abstract}

The Corporate social responsibility is an obligation of laws and regulations imposed on each company to pay attention to the surrounding environment where the company is located. The purpose of corporate social responsibility is to contribute to the welfare of the community and carry out sustainable development with local governments. The problem raised in this study is how the implementation of corporate legal obligations in providing corporate social responsibility in Karawang district. The method used is empirical juridical research. The conclusion is that there is no legal awareness for companies in Karawang Regency to give corporate social responsibility to the environment and Karawang Regency in general. In fact, according to statutory provisions, companies are required to provide corporate social responsibility as their obligation to carry out economic and community development in an area.

Keywords: Corporate Social Responsibility, Companies and Legal Obligation 
CORPORATE SOCIAL RESPONSIBILITY DI KABUPATEN KARAWANG : $M$. Gary Gagarin Akbar, Muhamad Abas, Lia Amaliya

\section{PENDAHULUAN}

Corporate social responsbility adalah komitmen perusahaan atau dunia bisnis untuk berkontriibusi dalam pengenbangan ekonomi yang berkelanjutan dengan memperhatikan tanggung jawab sisial perusahaan dan menitikberatkan pada keseimbangan antara perhatian terhadap aspek ekonomis, sosial, dan lingkungan. ${ }^{1}$

Corporate social responsbility atau yang dikenal dengan tanggung jawab sosial dan lingkungan merupakan kewajiban Perseroan Terbatas yang dianggarkan dan diperhitungkan sebagai biaya Perseroan Terbatas yang pelaksnaaannya memperhatikan kepatutan dan kewajaran. ${ }^{2}$

Kabupaten Karawang saat ini menjadi Kota Industri terbesar di Indonesia dan bahkan termasuk yang terbesar di kawasan Asia Tenggara. Jumlah Perusahaan yang ada di Karawang sampai dengan tahun 2019 mencapai kurang lebih 1.500 (seribu lima ratus) yang tersebar di berbagai kawasan industri mulai dari KIIC, Surya Cipta, dan lain sebagainya.

${ }^{1}$ Hendrik budi untung, Corporate Social Resposibility, (Jakarta : Sinar Grafika, 2008), hlm. 1.
Berkembang pesatnya perusahaan di Kabupaten Karawang menimbulkan dampak positif dan negatif. Dampak positifnya, perusahaan yang ada di Kabupaten Karawang dapat menyerap tenaga kerja dari penduduk lokal yang ada di Karawang dan meningkatkan perekonomian masyarakat. Kemudian, dampak negatif yang ditimbulkan antara lain dampak terhadap lingkungan. Oleh karena itu, di dalam peraturan perundangundangan mewajibkan perusahaan untuk memenuhi tanggung jawab sosial lingkungan perusahaan atau yang lebih dikenal dengan corporate social responsibility.

Kehadiran perusahaan yang ada di Kabupaten Karawang harusnya dapat menjadi keuntungan bagi pemerintah daerah untuk menjadi mitra dalam pembangunan di Kabupaten Karawang. Kabupaten Karawang sampai dengan saat ini memiliki banyak sekali permasalahan, diantaranya mengenai kesejahteraan masyarakat, banyak rumah tidak layak huni, fasilitas kesehatan yang belum memadai, dan banyaknya sekolah yang

2 Binoto Nadapdap, Hukum Perseroan Terbatas Berdasarkan Undang-Undang Nomor 40 Tahun 2007, (Jakarta: Permata Aksara, 2013), hlm. 138. 
CORPORATE SOCIAL RESPONSIBILITY DI KABUPATEN KARAWANG : $M$. Gary Gagarin Akbar, Muhamad Abas, Lia Amaliya

rusak sehingga tidak layak untuk dijadikan tempat belajar mengajar. Hal-hal tersebut pastinya tidak akan semuanya dapat ditutup melalui Anggaran Pendapatan dan Belanja Daerah (APBD), sehingga keberadaan corporate social responsibility dapat menjadi solusi bagi pemerintah daerah dalam melakukan pembangunan.

Menurut data yang diperoleh dari pihak pemerintah daerah diketahui bahwa sampai dengan tahun 2018 jumlah perusahaan yang tercatat memberikan Tanggung Jawab Sosial dan Lingkungan sebanyak 107 (seratus tujuh) perusahaan dari kurang lebih 1500 (seribu lima ratus) perusahaan yang ada di Kabupaten Karawang dengan jumlah total nomial kurang lebih Rp. 43.000.000.000 (empat puluh tiga milyar rupiah). Hal tersebut berarti pendapatan dari sektor Tanggung Jawab Sosial dan Lingkungan perusahaan yang ada di Kabupaten Karawang masih sangat sedikit. Berdasarkan hal tersebut maka penulis tertarik untuk melakukan penelitian dengan judul implementasi kewajiban hukum perusahaan dalam memberikan corporate social responsibility di Kabupaten Karawang.

\section{PERMASALAHAN}

Berdasarkan hal-hal yang telah dijelaskan di atas, maka muncul suatu rumusan masalah yaitu bagaimana implementasi kewajiban hukum perusahaan dalam memberikan corporate social responsibility di Kabupaten Karawang?

\section{METODE PENELITIAN}

Metode pendekatan yang digunakan dalam penelitian ini adalah yuridisnormatif. Selain itu penelitian ini juga menggunakan pendekatan studi lapangan sebagai pendukung berdasarkan ruang lingkup dan identifikasi masalah yang ada. Hal ini dimaksudkan agar penelitian ini sejauh mungkin dapat mengetahui mengenai urgensi pembaharuan kebijakan tentang perlindungan hukum terhadap guru di Indonesia secara detail yang bersumber dari beberapa aspek.

Untuk mengkaji pokok permasalahan, penelitian ini mempergunakan metode penelitian hukum normatif. Dengan meneliti bahan pustaka yang ada. Salah satunya dengan pendekatan perundangundangan. Karena yang akan diteliti adalah berbagai aturan hukum yang menjadi fokus sekaligus tema sentral suatu penelitian. Penelitian ini akan lebih menitikberatkan pada penelitian hukum normatif. Dengan menyesuaikan diri 
CORPORATE SOCIAL RESPONSIBILITY DI KABUPATEN KARAWANG : $M$. Gary Gagarin Akbar, Muhamad Abas, Lia Amaliya

dengan ruang lingkup dan identifikasi masalah yang telah dikemukakan diatas. Pendekatan yang bersifat yuridis-normatif tersebut akan dilakukan dengan mempergunakan bahan hukum primer, bahan hukum sekunder dan bahan hukum tersier.

\section{PEMBAHASAN}

\section{A. Pengaturan Hukum Mengenai} Corporate Social Responsibility di Indonesia

Corporate social responsbility adalah komitmen perusahaan atau dunia bisnis untuk berkontriibusi dalam pengenbangan ekonomi yang berkelanjutan dengan memperhatikan tanggung jawab sisial perusahaan dan menitikberatkan pada keseimbangan antara perhatian terhadap aspek ekonomis, sosial, dan lingkungan. ${ }^{3}$ Corporate social responsbility atau yang dikenal dengan tanggung jawab sosial dan lingkungan merupakan kewajiban Perseroan Terbatas yang dianggarkan dan diperhitungkan sebagai biaya Perseroan Terbatas

${ }^{3}$ Hendrik budi untung, Corporate Social Resposibility, (Jakarta : Sinar Grafika, 2008), hlm. 1. yang pelaksnaaannya memperhatikan kepatutan dan kewajaran. ${ }^{4}$

Ketentuan mengenai corporate social responsibility atau tanggung jawab sosial dan lingkungan perusahaan diatur dalam beberapa peraturan perundangan-undangan di Indonesia antara lain UndangUndang Nomor 19 Tahun 2003 tentang Badan Usaha Milik Negara, Undang-Undang Nomor 25 Tahun 2007 tentang Penanaman Modal, dan Undang-Undang Nomor 40 Tahun 2007 tentang Perseroan Terbatas.

Ketentuan tentang Tanggung Jawab Sosial dan Lingkungan yang pertama dapat kita lihat dalam Undang-Undang Nomor 19 tahun 2003 tentang Badan Usaha Milik Negara. Di dalam Undang-Undang ini khususnya Pasal 88 terdapat ketentuan bahwa BUMN harus memperhatikan masyarakat disekitar perusahaan. Pasal 88 menyatakan bahwa BUMN dapat menyisihkan sebagian laba bersihnya untuk keperluan pembinaan usaha kecil/koperasi serta pembinaan masyarakat sekitar BUMN.

4 Binoto Nadapdap, Hukum Perseroan Terbatas Berdasarkan Undang-Undang Nomor 40 Tahun 2007, (Jakarta: Permata Aksara, 2013), hlm. 138. 
CORPORATE SOCIAL RESPONSIBILITY DI KABUPATEN KARAWANG : $M$. Gary Gagarin Akbar, Muhamad Abas, Lia Amaliya

Selanjutnya di dalam Pasal 90 menyatakan bahwa BUMN dalam batas kepatutan hanya dapat memberikan donasi untuk amal atau tujuan sosial sesuai dengan ketentuan peraturan perundang-undangan.

Undang-Undang Nomor 25 Tahun 2007 tentang Penanaman Modal. Menurut Pasal 15 huruf b Undang-Undang Nomor 25 Tahun 2007 tentang Penanaman Modal mengatur bahwa setiap penanam modal wajib melaksanakan Tanggung Jawab Sosial dan Lingkungan. Di dalam penjelasan Pasal 15 huruf $b$ tersebut menyatakan bahwa Tanggung Jawab Sosial dan Lingkungan adalah tanggung jawab yang melekat pada setiap perusahaan penanaman modal untuk tetap menciptakan hubungan yang serasi, seimbang, dan sesuai dengan lingkungan, nilai, norma, dan budaya masyarakat setempat.

Pasal 16 Undang-Undang Nomor 25 Tahun 2007 tentang Penanaman Modal mengatur bahwa setiap penanam modal bertanggung jawab untuk menjaga kelestarian lingkungan hidup. Ketentuan dalam pasal ini berkaitan dengan Tanggung Jawab Sosial dan Lingkungan. Untuk menandakan bahwa Tanggung Jawab Sosial dan Lingkungan merupakan kewajiban hukum dan bukan kewajiban moral, maka terdapat sanksi dalam UU ini. Selanjutnya Pasal 34 UU Penanaman Modal menyatakan bahwa jika penanam modal tidak melakukan kewajibannya untuk melaksanakan Tanggung Jawab Sosial dan Lingkungan maka penanam modal dapat dikenai sanksi administratif berupa :

a. Peringatan tertulis

b. Pembatasan kegiatan usaha;

c. Pembekuan kegiatan usaha dan/atau fasilitas penanam modal; atau

d. Pencabutan kegiatan usaha dan/atau fasilitas penanaman modal.

Selain dikenai sanksi administratif, penanam modal juga dapat dikenai sanksi lain sesuai peraturan perundang-undangan yang berlaku menurut Pasal 34 ayat (3) UU Penanaman Modal.

Ketentuan selanjutnya dapat kita lihat dalam Undang-undang Nomor 40 Tahun 2007 tentang Perseroan Terbatas. Menurut Pasal 1 angka 3 Undang-undang Nomor 40 Tahun 2007 tentang Perseroan Terbatas 
CORPORATE SOCIAL RESPONSIBILITY DI KABUPATEN KARAWANG : $M$. Gary Gagarin Akbar, Muhamad Abas, Lia Amaliya

menyebutkan bahwa Tanggung Jawab Sosial dan Lingkungan adalah komitmen Perseroan untuk berperan serta dalam pembangunan ekonomi berkelanjutan guna meningkatkan kualitas kehidupan dan lingkungan yang bermanfaat, baik bagi Perseroan sendiri, komunitas setempat, maupun masyarakat pada umumnya.

Selanjutnya, di dalam Pasal 74 ayat (1), (2), dan (3) Undang-Undang Perseroan Terbatas menyatakan bahwa :

1. Tanggung Jawab Sosial Lingkungan wajib untuk perseroan yang menjalankan kegiatan usahanya di bidang dan/atau berkaitan dengan sumber daya alam.

Yang dimaksud dengan "perseroan yang menjalankan kegiatan usahanya di bidang sumber daya alam" adalah perseroan yang kegiatannya mengelola dan memanfaatkan sumber daya alam. Sedangkan yang dimaksud dengan "perseroan yang menjalankan kegiatan usahanya yang berkaitan dengan sumber daya alam" adalah perseroan yang tidak memanfaatkan sumber daya alam, tetapi kegiatan usahanya berdampak pada fungsi kemampuan sumber daya alam.

2. Tanggung Jawab Sosial Lingkungan merupakan kewajiban perseroan yang dianggarkan dan diperhitungkan sebagai biaya perseroan yang pelaksanaannya dilakukan dengan memperhatikan kepatutan dan kewajaran.

3. Mengenai sanksi, perseroan yang tidak melaksanakan kewajiban Tanggung Jawab Sosial Lingkungan akan dikenai sanksi sesuai dengan ketentuan peraturan perundang-undangan yang berlaku.

Kemudian di dalam Pasal 4 Peraturan Pemerintah Nomor 47 Tahun 2012 tentang Tanggung Jawab Sosial Lingkungan Perseroan Terbatas berbunyi Tanggung Jawab Sosial Lingkungan dilaksanakan oleh Direksi berdasarkan rencana kerja tahunan perseroan setelah mendapat mendapat persetujuan Dewan Komisaris atau Rapat Umum Pemegang Saham (RUPS) sesuai dengan anggaran dasar perseroan. Rencana kerja tahunan perseroan tersebut memuat rencana dan 
CORPORATE SOCIAL RESPONSIBILITY DI KABUPATEN KARAWANG : $M$. Gary Gagarin Akbar, Muhamad Abas, Lia Amaliya

anggaran yang dibutuhkan untuk pelaksanaan Tanggung Jawab Sosial Lingkungan. Selanjutnya, Pasal 6 Peraturan Pemerintah Nomor 47 Tahun 2012 tentang Tanggung Jawab Sosial Lingkungan Perseroan Terbatas menyatakan bahwa pelaksanaan Tanggung Jawab Sosial Lingkungan tersebut dimuat dalam laporan tahunan perseroan dan dipertanggungjawabkan kepada RUPS.

Berdasarkan hal-hal tersebut di atas, ketentuan mengenai Tanggung Jawab Sosial dan Lingkungan Perusahan atau Corporate Social Responsibility (CSR) telah dijamin oleh ketentuan peraturan perundangundangan, sehingga setiap perusahaan yang ada wajib melaksanakan ketentuan tersebut.

\section{B. Implementasi Kewajiban Hukum} Perusahaan Dalam Memberikan Corporate Social Responsibility Di Kabupaten Karawang

Di dalam Pasal 1 angka 3 UUPT menyatakan bahwa Tanggung Jawab Sosial dan Lingkungan adalah komitmen perseroan untuk berperan serta dalam pembangunan ekonomi berkelanjutan guna meningkatkan kualitas kehidupan dan lingkungan yang bermanfaat, baik bagi perseroan sendiri, komunitas setempat, maupun masyarakat pada umumnya.

Kabupaten Karawang adalah sebuah kabupaten di Provinsi Jawa Barat, yang memiliki luas wilayah 1.737,53 km2 , dengan jumlah penduduk sekitar 2.370.488 jiwa (sensus 2019). Selain dijuluki sebagai kota lumbung padi, Kabupaten Karawang pada masa kini dijuluki dengan sebutan Kota Industri. Hal ini dibuktikan dengan penyedian lahan oleh Pemerintah Daerah untuk sektor industri adalah seluas 13.756.358 hektar yang tersebar kedalam beberapa kawasan industri di Kabupaten Karawang yakni antara lain Kawasan Industri Kujang, Kawasan Industri Indotaisae, Kawasan Industri Mandala Putra, Kawasan Industri Karawang International Industrial City (KIIC), Kawasan Industri Suryacipta dan Kawasan Industri Mitra (KIM). Kawasan tersebut tentunya di tempati oleh berbagai perusahaan, baik perusahaan dalam negeri maupun perusahaan dengan modal asing. Berdasarkan data dari Dinas Tenagakerja dan Transmigrasi 
CORPORATE SOCIAL RESPONSIBILITY DI KABUPATEN KARAWANG : $M$. Gary Gagarin Akbar, Muhamad Abas, Lia Amaliya

Kabupaten Karawang, Jumlah Perusahaan per tahun 2018 adalah 1.762 pabrik. Dengan rincian nya adalah pabrik swasta sebanyak 787 , Penanaman Modal Dalam Negeri sebanyak 269, Penanaman Modal Asing sebanyak 638, dan Join Venture tercatat sebanyak 58 perusahaan.

Berdasarkan data dari Badan Pusat Statistik Kabupaten Karawang disebutkan bahwa angka kemiskinan masyarakat kabuten Karawang adalah sebanyak 187,96 ribu jiwa. Dengan data tersebut mengartikan bahwa, pemerintah masih memiliki pekerjaan rumah dalam mensejahterakan masyarakatnya tersebut. Sehingga dalam hal ini, pemerintah Kabupaten Karawang memiliki tanggungjawab yang besar terhadap kesejahteraan masyrakatnya, terutama bagi kelompok yang belum sejahtera. Salah satu cara untuk dapat meningkatkan capaian masayarakat Kabupaten yang sejahtera adalah dengan adanya partisipasi aktif dan berkelanjutan dari perusahaan yang tersebar di wilayah Kabupaten Karawang melalui dana realisasi program Corporate Sosial Responsbility.
Tanggung jawab sosial lingkungan perusahaan, merupakan salah satu pendukung pemerintah daerah dalam menyelenggarakan kesejahteraan masayarakatnya, hal ini berlaku pula di Kabupaten Karawang yang mana tersebar di beberapa daerah di Kabupaten Karawang perusahaan-perusahaan lokal maupun persekutuan modal asing.

Tanggung jawab sosial perusahaan atau yang lebih dikenal dengan CSR atau tanggung jawab sosial lingkungan perusahaan merupakan salah satu esensi yang harus diberikan perusahaan kepada lingkungan sosial dimana perusahaan berada. Secara konseptual definisi tanggung jawab sosial perusahaan dapat diringkas sebagai tanggung jawab sosial perusahaan untuk menciptakan keseimbangan antara kondisi sosial, ekonomi dan lingkungan dimana perusahaan berada. Secara umum tanggung jawab sosial perusahaan merupakan tanggung jawab etis yang harus dibayarkan perusahaan kepada perusahaan, masyarakat atau masyarakat, dan pemangku kepentingan di lingkungan ekologi / lingkungan. Oleh karena itu, 
CORPORATE SOCIAL RESPONSIBILITY DI KABUPATEN KARAWANG : $M$. Gary Gagarin Akbar, Muhamad Abas, Lia Amaliya

keberadaan perusahaan harus mampu memberikan dampak dan tanggung jawab sosial bagi para pemangku kepentingan, masyarakat dan lingkungan tempat perusahaan beroperasi

Beberapa perusahaan di Kabupaten Karawang melaksanakan rencana tanggung jawab sosial perusahaan berdasarkan data yang diperoleh penulis dari Badan Perencanaan dan Pembangunan Daerah Kabupaten Karawang. Mereka menyampaikan bahwa tidak semua perusahaan berkontribusi dalam pelaksanaan tanggung jawab sosial perusahaan melalui pemerintah daerah. Pada tahun 2019 hanya 700 perusahaan. Pembangunan Kabupaten Karawang. Namun, Dari perspektif konsep pelaksanaan rencana realisasi CSR melalui pemerintah daerah, hanya 107 perusahaan telah menerapkan konsep ini sesuai dengan konsep dan wujud manusia (filantrofis) melalui pemerintah daerah dalam memenuhi kewajiban hukum rencana tanggung jawab sosial dan lingkungan perusahaan.

Permasalahan yang dihadapi oleh pemerintah daerah terkait dengan
Tanggung Jawab Sosial dan Lingkungan Perusahaan atau corporate social responsibility yaitu:

1. Kurangnya kesadaran hukum dari perusahaan mengenai kewajiban hukum untuk memberikan Tanggung Jawab Sosial dan Lingkungan Perusahaan atau corporate social responsibility.

2. Pemerintah daerah belum memiliki payung hukum yang jelas untuk dapat memaksa perusahaan memberikan Tanggung Jawab Sosial dan Lingkungan Perusahaan atau corporate social responsibility, sehingga pemerintah hanya berharap pada kesadaran hukum dari setiap perusahaan.

3. Perusahaan memiliki asumsi dan argumentasi yang berbedabeda mengenai Tanggung Jawab Sosial dan Lingkungan Perusahaan atau corporate social responsibility, sehingga sulit ketika implementasi di lapangan.

4. Banyak perusahaan yang melakukan pemberian Tanggung Jawab Sosial dan Lingkungan Perusahaan atau 
CORPORATE SOCIAL RESPONSIBILITY DI KABUPATEN KARAWANG : $M$. Gary Gagarin Akbar, Muhamad Abas, Lia Amaliya

corporate social responsibility secara langsung kepada masyarakat sehingga banyak ketidakjelasan sasaran dalam penggunaannya.

5. Di Kabupaten Karawang sebenarnya memiliki Tim Fasilitasi Tanggung Jawab Sosial dan Lingkungan Perusahaan yang diisi oleh dinas-dinas terkait yang bertujuan memfasilitasi perusahaan yang akan memberikan Tanggung Jawab Sosial dan Lingkungan Perusahaan atau corporate social responsibility. Namun, keberadaan tim fasilitasi tersebut tidak berjalan optimal karena tidak ada aturan yang mengharuskan perusahaan memberikan Tanggung Jawab Sosial dan Lingkungan Perusahaan atau corporate social responsibility melalui tim ini.

6. Banyak juga perusahaan yang melakukan pemberian Tanggung Jawab Sosial dan Lingkungan Perusahaan atau corporate social responsibility langsung kepada masyarakat dikarenakan tidak adanya faktor kepercayaan kepada pihak pemerintah daerah atau tim fasilitasi untuk melaksanakan Tanggung Jawab Sosial dan Lingkungan Perusahaan atau corporate social responsibility.

Berdasarkan permasalahan yang telah diuraikan di atas, maka pemerintah daerah Kabupaten Karawang saat ini berinisiatif untuk membuat Peraturan Daerah yang akan mengatur mengenai corporate social responsibility. Harapannya ke depan, perusahaan yang ada di Kabupaten Karawang harus memberikan kewajiban CSR kepada masyarakat melalui tim yang akan dibentuk oleh pemerintah daerah dengan tujuan agar terkontrol dan diawasi dengan baik pelaksanaannya. Ke depan pemeberian CSR di Kabupaten Karawang akan dilakukan melalui 1 (satu) pintu yang bertujuan agar pemerintah daerah dapat mengawasi pelaksanaan CSR.

Tim yang akan dibentuk oleh pemerintah daerah, nantinya akan menyiapkan "buku menu" untuk dapat dipilih oleh para perusahaan, misalnya di bidang pendidikan, kesehatan, infrastruktur, dan lain 
CORPORATE SOCIAL RESPONSIBILITY DI KABUPATEN KARAWANG : $M$. Gary Gagarin Akbar, Muhamad Abas, Lia Amaliya

sebagainya. Hal ini dilakukan agar kontribusi dari CSR dapat dirasakan manfaatnya oleh masyarakat Kabupaten Karawang dan dapat membantu percepatan pembangunan Kabupaten Karawang pada umumnya.

\section{KESIMPULAN}

Berdasarkan hasil penelitian dan pembahasan maka dapat disimpulkan penelitian ini sebagai berikut:

1. Ketentuan mengenai corporate social responsibility atau tanggung jawab sosial dan lingkungan perusahaan telah diatur dalam beberapa peraturan perundangan-undangan di Indonesia antara lain Undang-Undang Nomor 19 Tahun 2003 tentang Badan Usaha Milik Negara, Undang-Undang Nomor 25 Tahun 2007 tentang Penanaman Modal, dan UndangUndang Nomor 40 Tahun 2007 tentang Perseroan Terbatas dan beberapa peraturan turunan lainnya.

2. Implementasi corporate social responsibility di Kabupaten Karawang belum berjalan dengan baik. hal tersebut terbukti bahwa di Kabupaten Karawang yang menurut data terdapat lebih dari 1000 (seribu) perusahaan, namun yang tercatat dan terpantau memberikan corporate social responsibility hanya kurang lebih 107 (seratus tujuh) perusahaan saja. Sehingga pemerintah daerah saat ini sedang merancang peraturan daerah tentang corporate social responsibility untuk dapat mengawasi dan menjamin pelaksanaan corporate social responsibility di Kabupaten Karawang dapat terselenggara dengan baik.

\section{DAFTAR PUSTAKA}

\section{A. BUKU-BUKU}

Abdulkadir Muhammad, Hukum Perdata Indonesia, Cetakan Revisi (Bandung: Citra Aditya Bakti,2010)

Prasetio, Dilema BUMN, Benturan Penerapan Business Judgement Rule (BJR) dalam keputusan Bisnis Direksi BUMN, Cet.1 (Jakarta: Rayyana komunikasindo: 2014) 
CORPORATE SOCIAL RESPONSIBILITY DI KABUPATEN KARAWANG : $M$. Gary Gagarin Akbar, Muhamad Abas, Lia Amaliya

Binoto Nadapdap, Hukum Perseroan

Terbatas Berdasarkan Undang-

Undang Nomor 40 Tahun 2007,

(Jakarta: Permata Aksara, 2013)

Hendrik budi untung, Corporate

Social Resposibility, (Jakarta :

Sinar Grafika, 2008)

Munir Fuady, Perseroan Terbatas

Paradigma Baru, Cet.1 (Bandung:

Citra Aditya Bakti, 2003)

Ridwan Khairandy, Perseroan

Terbatas Doktrin, Peraturan

Perundang-undangan, dan

Yurisprudensi, Cet.2 (Yogyakarta:

Kreasi Total Media,2009)
Undang-Undang Nomor 40 Tahun

2007 Tentang Perseroan

Terbatas;

Peraturan Pemerintah Nomor 47

Tahun 2012 tentang

TanggungJawab Sosial

dan Lingkungan Perseroan

Terbatas;

C. SUMBER LAIN

Agus Salim Harahap, Pengaturan

Corporate Social

Responsibility (Csr) Di

Indonesia, Lex Jurnalica

Volume 7 Nomor 3, Agustus

2010

\section{B. PERATURAN PERUNDANG-}

\section{UNDANGAN}

Undang-Undang Nomor 19 Tahun

2003 tentang Badan

Usaha Milik Negara;

Undang-Undang Nomor 25 Tahun

2007 Tentang Penanaman

Modal; 